\title{
Outcomes Associated with Conventional Accelerated Versus Once-Weekly IV Iron Therapy in Outpatients Undergoing Hemodialysis
}

\author{
Marta Malkinska, Wasim S El Nekidy, Maher M El-Masri, Albert Kadri, Christine Donaldson, \\ and Derrick Soong
}

\begin{abstract}
Background: Although parenteral iron replacement is a key aspect of managing anemia in patients who are undergoing hemodialysis, studies evaluating novel iron dosing regimens are scarce.

Objective: To compare the effectiveness of a once-weekly IV iron dosing strategy with that of a conventional accelerated iron dosing regimen in patients undergoing hemodialysis.

Methods: In this retrospective cohort study, patient-specific information was collected for individuals undergoing hemodialysis who received IV iron between June 1, 2010, and June 30, 2012, at a community hospital in southwestern Ontario. The primary outcomes were hemoglobin level and utilization of an erythropoiesis-stimulating agent for 2 groups of patients: those receiving iron according to a once-weekly IV regimen and those receiving iron by a conventional accelerated IV regimen.

Results: Of the 148 patients who met the inclusion criteria, 99 (66.9\%) received iron by a conventional accelerated regimen and $49(33.1 \%)$ by a once-weekly IV regimen. Generalized estimating equations developed from 313 observations obtained from these 148 patients suggested that average transferrin saturation percentage and iron concentration were both significantly higher in the group that received iron once weekly than in the group that received iron by the conventional accelerated regimen ( $p=0.014$ and 0.008 , respectively). The mean weekly dose of erythropoiesis-stimulating agent was significantly lower in the once-weekly administration group than in the conventional administration group (7419 versus 10706 units; $p=0.041$ ). The 2 groups did not differ significantly in terms of hemoglobin concentration $(p=0.46)$ or ferritin level $(p=0.13)$.
\end{abstract}

Conclusions: The findings of this study suggest that a once-weekly iron dosing regimen may be superior to a conventional accelerated dosing regimen for managing iron deficiency anemia in patients who are undergoing hemodialysis.

Keywords: parenteral iron, pharmacist dosing, outpatient

\section{RÉSUMÉ}

Contexte : Bien que la recharge en fer par voie parentérale représente un facteur clé de la prise en charge de l'anémie de patients traités par hémodialyse, il n'y a que très peu d'études évaluant les nouveaux schémas posologiques de fer.

Objectif : Comparer l'efficacité réelle d'une dose hebdomadaire de fer administrée par voie intraveineuse à celle d'un schéma posologique intensif traditionnel de fer chez les patients hémodialysés.

Méthodes : Dans la présente étude de cohorte rétrospective, on a recueilli des données sur des patients traités par hémodialyse qui ont reçu du fer par voie intraveineuse entre le 1er juin 2010 et le 30 juin 2012 dans un hôpital communautaire du sud-ouest de l'Ontario. Les principaux paramètres d'évaluation étaient le taux d'hémoglobine et l'emploi d'un agent stimulant l'érythropoïèse chez deux groupes de patients : l'un recevant du fer à raison d'une dose hebdomadaire par voie intraveineuse et l'autre selon un schéma posologique intensif traditionnel par voie intraveineuse.

Résultats : Parmi les 148 patients ayant satisfait aux critères d'admissibilité, $99(66,9 \%)$ ont reçu du fer selon un schéma posologique intensif traditionnel et $49(33,1 \%)$ l'ont reçu à raison d'une dose hebdomadaire par voie intraveineuse. Des équations d'estimation généralisée élaborées à partir de 313 observations obtenues de ces 148 patients laissent croire que les pourcentages moyens de saturation de la transferrine et de la concentration de fer étaient tous deux nettement plus élevés dans le groupe ayant reçu du fer une fois par semaine que dans le groupe en ayant reçu selon le schéma posologique intensif traditionnel (respectivement $p=0,014$ et 0,008 ). La dose hebdomadaire moyenne d'un agent stimulant l'érythropoï̀se était significativement plus faible au sein du groupe recevant une dose de fer hebdomadaire que dans le groupe de traitement traditionnel (7419 contre 10706 unités; $p=0,041)$. Les taux d'hémoglobine $(p=0,46)$ ou de ferritine $(p=0,13)$ ne variaient pas de façon significative entre les deux groupes.

Conclusions : Selon les résultats de la présente étude, une dose hebdomadaire de fer serait plus efficace que le schéma posologique intensif traditionnel pour traiter l'anémie par carence en fer chez les patients hémodialysés. 
Mots clés : fer parentéral, ajustement posologique par le pharmacien, patient externe

\section{INTRODUCTION}

$\mathrm{P}$ atients requiring hemodialysis commonly experience anemia for multiple reasons, such as deficiency of erythropoietin and iron, loss of blood during hemodialysis, and frequent blood sampling for laboratory investigations. Anemia puts these patients at increased risk for adverse cardiovascular events, such as left ventricular hypertrophy, need for blood transfusion, and decline in quality of life. ${ }^{1}$ To minimize these adverse outcomes, administration of erythropoiesis-stimulating agents (ESAs) and IV administration of iron are recommended. ${ }^{1}$ The Kidney Disease Outcomes Quality Initiative (KDOQI) of the National Kidney Foundation, the Kidney Disease Improving Global Outcomes (KDIGO) initiative, and the Canadian Society of Nephrology (CSN) all recommend the use of IV iron and/or ESAs to achieve a hemoglobin level of 95 to $120 \mathrm{~g} / \mathrm{L}$ (KDOQI target 110-120 g/L; KDIGO target 100-115 g/L; CSN target $100-110 \mathrm{~g} / \mathrm{L}$, with a range of $95-115 \mathrm{~g} / \mathrm{L}$ ) in patients undergoing hemodialysis. ${ }^{1-5}$ Iron stores in the body are measured in terms of transferrin saturation (TSAT) and serum ferritin. The KDOQI and CSN guidelines recommend IV administration of iron to maintain serum ferritin between 200 and $500 \mu \mathrm{g} / \mathrm{L}$ and TSAT between $20 \%$ and $50 \%$ for patients undergoing hemodialysis who require ESAs, ${ }^{1,2}$ whereas the KDIGO guidelines suggest a trial of IV iron if TSAT is less than or equal to $30 \%$ and ferritin is less than or equal to $500 \mu \mathrm{g} / \mathrm{L} .{ }^{4}$

However, the benefits of ESAs must be weighed against the potential harms that have been identified in post hoc analyses of randomized trials involving patients with anemia and chronic kidney disease. ${ }^{6-9}$ Subsequent analysis of these trials led both Health Canada and the US Food and Drug Administration to issue recommendations to titrate the ESA dose to more conservative hemoglobin levels. ${ }^{10,11}$

Given these warnings and the considerable cost of ESA to the Canadian health care system, the use of parenteral iron has been advocated for its ESA-sparing effects. ${ }^{12}$ Unfortunately, IV formulations of iron also have the potential to harm patients, ${ }^{13,14}$ with higher monthly doses being associated with higher risks. Bailie and others ${ }^{14}$ observed a $12 \%$ increase in the risk of all-cause mortality among patients who received an IV iron dose of at least $300 \mathrm{mg} / \mathrm{month}$ relative to those who received less than $300 \mathrm{mg} / \mathrm{month}$ and an $18 \%$ increase in the risk of all-cause mortality with a 4-month course of at least $400 \mathrm{mg} / \mathrm{month}$ relative to a 4-month course of less than $300 \mathrm{mg} / \mathrm{month} .{ }^{14} \mathrm{In}$ addition, they observed a $12 \%$ increase in the risk of hospital admission with a 4-month course of at least $300 \mathrm{mg} / \mathrm{month}$. These authors speculated that endothelial and immune dysfunction, as well as inflammation, generated through the formation of superoxide and hydroxyl free radicals in the body, could lead to higher morbidity and mortality secondary to the use of IV iron. Administration of IV iron releases proinflammatory cytokines, ${ }^{15}$ which are believed to be responsible for hypersensitivity reactions; this situation led Health Canada to mandate that product monographs for all commercially available IV iron formulations ${ }^{16-19}$ include a suitable warning.

To balance the benefits of ESAs and IV iron without exposing patients to excessive risk, the renal pharmacists at the study institution developed a novel, stepwise, pharmacist-driven anemia management protocol for coadministration of ESA and IV iron in iron-deficient patients, whereby IV iron was initiated according to an accelerated approach based on the dosing recommendations of the respective product monographs. After publication of an FDA drug safety communication concerning ESAs in $2011^{20}$ and subsequent review of the pertinent literature, and with the collaboration of hospital nephrologists, an amended protocol was created to fine-tune the use of ESA (Appendix 1) and IV iron, whereby IV iron was initiated according to a onceweekly regimen.

Two IV iron agents were used at the study institution during the study period: sodium ferric gluconate and iron dextran. According to the respective product monographs, the conventional accelerated dosing protocol for both formulations includes administration to iron-deficient patients (TSAT less than 20\% and/or ferritin less than $200 \mu \mathrm{g} / \mathrm{L}$ ), with a total initial dose of $1 \mathrm{~g}$, typically administered over 8 to 10 consecutive dialysis sessions, followed by monthly maintenance doses. ${ }^{16,18}$ For sodium ferric gluconate, $125 \mathrm{mg}$ is administered per dialysis session for a total of 8 consecutive sessions, followed by a monthly maintenance dose of $125 \mathrm{mg}^{21}$; for iron dextran, $100 \mathrm{mg}$ is administered per dialysis session for a total of 10 consecutive sessions, followed by a monthly maintenance dose of $100 \mathrm{mg} .{ }^{22}$

Multiple studies have investigated various accelerated irondosing strategies, as well as the use of low maintenance doses (i.e., weekly or biweekly instead of monthly) ${ }^{23-26}$; however, none have compared the effectiveness of once-weekly iron administration with a conventional accelerated dosing strategy for patients undergoing hemodialysis. Given the lack of published literature 
in this area, the primary purpose of this study was to compare various outcomes (hemoglobin concentration, ESA utilization, and iron indices) for patients who received iron by a conventional accelerated dosing regimen and those who received IV iron by a once-weekly regimen.

\section{METHODS}

\section{Design and Study Population}

This study, approved by the Windsor Regional Hospital Research Ethics Board, was a retrospective chart review conducted at a regional hemodialysis centre in southwestern Ontario. The review included all outpatients undergoing hemodialysis who received IV iron between June 1, 2010, and June 30, 2012. This 2-year timeframe was chosen because the transition from the conventional accelerated IV iron protocol to the once-weekly IV iron protocol commenced on June 1, 2011 (i.e., midpoint of the study period). The aim of the change in protocol was to minimize build-up of pro-inflammatory cytokines caused by consecutive doses of IV iron, but it also helped to standardize the administration process for nursing staff, minimizing the risk of doses being missed (i.e., IV iron is given only on Wednesdays or Thursdays, depending on each patient's hemodialysis schedule). There were no other significant changes during the study period that could have affected hemodialysis operating procedures or patient therapy. All data were collected from the electronic records of individual patients and were entered into a computerized database.

All patients undergoing hemodialysis who were at least 18 years old and who had received IV iron therapy for at least 3 months between June 1, 2010, and June 30, 2012, were eligible for inclusion in the study. The following patients were excluded: those who had received IV iron therapy for less than 3 months in the specified period, those with a contraindication to iron therapy, those who refused IV iron therapy, those who had received darbepoetin alfa instead of epoetin alfa as the ESA of choice (to facilitate dosing calculations), those who had received both conventional accelerated and once-weekly iron therapy (to ensure independence of group comparisons), those who were pregnant, and/or those with an alternative cause of anemia (other than deficiency of erythropoietin hormone or iron).

\section{Definition of Variables}

Iron indices (TSAT and iron and ferritin levels) were measured quarterly, whereas hemoglobin was measured monthly. Pharmacists documented and evaluated these values using an anemia management protocol.

Each patient's iron regimen was classified as either "conventional accelerated" or "once-weekly" according to the timing and frequency of medication administration. In the control period (June 2010 to May 2011), patients with iron-deficiency anemia (i.e., TSAT less than $20 \%$ and/or ferritin less than $200 \mu \mathrm{g} / \mathrm{L}$ ) received iron by the conventional accelerated regimen, with IV iron administered for a total of 8 (sodium ferric gluconate) or 10 (iron dextran) consecutive dialysis sessions, followed by monthly maintenance doses, as described in the Introduction. In the intervention period (June 2011 to June 2012), patients received iron doses once weekly for 12 weeks (between measurements of iron indices), followed by monthly maintenance doses similar to those for the group that received conventional accelerated dosing. For patients with systemic infections, IV iron administration was held during treatment and was resumed once the antibiotic regimen was completed. The target hemoglobin level was 100 $120 \mathrm{~g} / \mathrm{L}$ based on the KDOQI 2007 and CSN 2008 targets. ${ }^{1,2}$ In both protocols, the pharmacist or physician could deviate from the protocol at his or her own discretion at any time, as deemed appropriate (e.g., if there was a sudden change in hemoglobin due to upcoming surgery or gastrointestinal bleeding).

\section{Data Analysis}

Data were analyzed using IBM SPSS Statistics for Windows, version 20.0 (released 2011; IBM Corporation, Armonk, New York). Basic descriptive statistics were used to describe the sample characteristics for the control and intervention groups (conventional accelerated and once-weekly regimens, respectively), which were compared using $\chi^{2}$ and $t$ tests. Because the patients in this study received multiple iron doses over time, multivariate generalized estimating equations (GEEs) were developed to compare the 2 groups for each of the outcomes, with adjustment for confounding variables and the correlated nature of the observations. Data for the variables TSAT, hemoglobin, ferritin level, iron level, and total amount of ESA administered were significantly skewed, so these variables were analyzed using square root transformation techniques to ascertain their normal distribution. All baseline and demographic characteristics that differed between the 2 groups were included in the GEE analyses, to adjust for the potential confounding effect of these variables on the outcome estimates. However, the final models of the GEE analyses included significant predictors, to ensure that the final models were parsimonious (i.e., provided optimal explanation of the outcome variables using the fewest possible variables). Statistical significance was based on $95 \%$ confidence intervals (CIs) or 2-tailed $\alpha$ of 0.05 .

\section{RESULTS}

\section{Baseline Characteristics}

Of 567 patients with chronic kidney disease (stages 3 to 5) who received IV iron therapy during the study period, 148 met the inclusion criteria: 99 who were undergoing hemodialysis and received iron by the conventional accelerated regimen and 49 who were undergoing hemodialysis and received iron by a once- 
weekly regimen. This sample of 148 patients yielded a total of 313 observations (228 in the conventional accelerated group and 85 in the once-weekly group), for an average of just over 2 observations per patient. The overall mean age of study participants was 68.2 (standard deviation 15.6) years, and men constituted $96(64.9 \%)$ of the sample. The 2 groups differed with regard to dry weight $(t=-2.69, p<0.001)$ and duration of dialysis $(t=5.42, p<0.001)$ (Table 1). They also differed with regard to iron products received: $75(76 \%)$ of the 99 patients in the conventional accelerated group received iron dextran, whereas $35(71 \%)$ of the 49 patients in the once-weekly group received sodium ferric gluconate $(p<0.001)$. Baseline ESA requirements were higher in the conventional accelerated group $(p=0.005)$.

\section{Outcomes}

The multivariate GEE results displayed in Table 2 indicate that the groups did not differ significantly with regard to hemoglobin concentration (Wald $z=0.54, p=0.46$ ) or ferritin level (Wald $z=2.34, p=0.13$ ). Although average TSAT percentage
(Wald $z=5.99, p=0.014$ ) and iron levels (Wald $z=7.04$, $p=0.008)$ were significantly higher in the once-weekly group, ESA utilization (Wald $z=4.18, p=0.041$ ) was significantly lower (by about 20\%) in the once-weekly group. There was no significant difference between the groups in achievement of the target TSAT level of $20 \%$ or more: for patients in the conventional accelerated dosing group, 147 (64.5\%) of the 228 observations showed achievement of the target TSAT level, whereas for patients in the once-weekly group, 60 (70.6\%) of the 85 observations showed achievement of the target TSAT level $(p=0.35)$.

\section{DISCUSSION}

Standardizing IV iron administration to a weekly dose in an outpatient hemodialysis setting is a simple, easy-to-implement process that can minimize missing doses and potentially minimize drug utilization costs. At the study institution, administering IV iron by the conventional accelerated method was frustrating for nurses and those involved in interpreting laboratory results for anemia. Despite using an electronic medical

Table 1. Comparison of Baseline Characteristics for Patients Who Received Iron Therapy by Conventional Accelerated or Once-Weekly Dosing Regimen

\begin{tabular}{|c|c|c|c|c|}
\hline \multirow[b]{2}{*}{ Variable } & \multicolumn{2}{|c|}{$\begin{array}{l}\text { Iron Administration Protocol; } \\
\text { Mean } \pm \text { SD or No. (\%) of Patients }\end{array}$} & \multirow[b]{2}{*}{$t$ or $\chi^{2}$ Value } & \multirow[b]{2}{*}{$p$ Value } \\
\hline & $\begin{array}{l}\text { Conventional Accelerated } \\
\qquad(n=99)\end{array}$ & $\begin{array}{c}\text { Once Weekly } \\
(n=49)\end{array}$ & & \\
\hline Age (years) & $67.6 \pm 16.0$ & $69.4 \pm 15.0$ & -0.65 & 0.52 \\
\hline Dry weight (kg) & $72.9 \pm 22.6$ & $83.1 \pm 19.6$ & -2.69 & $<0.001$ \\
\hline \multicolumn{3}{|l|}{ Sex } & 3.76 & 0.07 \\
\hline Male & $(60)$ & (76) & & \\
\hline Female & (40) & (24) & & \\
\hline Hypertension* & (93) & (80) & 5.37 & 0.028 \\
\hline Diabetes mellitus & (55) & $33 \quad(67)$ & 2.25 & 0.16 \\
\hline Heart disease† & $38 \quad(38)$ & $27 \quad(55)$ & 3.71 & 0.08 \\
\hline Liver disease & $5 \quad(5)$ & $1 \quad(2)$ & 0.86 & 0.66 \\
\hline \multicolumn{2}{|l|}{ Status at end of study } & & 19.05 & $<0.001$ \\
\hline Death & (29) & & & \\
\hline Transplant & (6) & $1 \quad(2)$ & & \\
\hline Transfer & $(2)$ & $0 \quad(0)$ & & \\
\hline Continuing dialysis & (63) & $47 \quad(96)$ & & \\
\hline Received transfusion & $(21)$ & $10 \quad(20)$ & 0.01 & $>0.99$ \\
\hline \multicolumn{2}{|l|}{ Iron product } & \multirow{3}{*}{$\begin{array}{ll}14 & (29) \\
35 & (71)\end{array}$} & 30.75 & $<0.001$ \\
\hline Iron dextran & $75 \quad(76)$ & & & \\
\hline Sodium ferric gluconate & (24) & & & \\
\hline \multicolumn{5}{|l|}{ Baseline data } \\
\hline Average TSAT percentage & $17.4 \pm 07.6$ & $16.3 \pm 7.0$ & 1.81 & 0.24 \\
\hline Iron $(\mu \mathrm{mol} / \mathrm{L})$ & $6.78 \pm 3.36$ & $6.96 \pm 3.16$ & -0.435 & 0.66 \\
\hline Hemoglobin (g/L) & $110.20 \pm 11.75$ & $107.91 \pm 12.65$ & 1.51 & 0.13 \\
\hline Weekly ESA utilization (units) & $11915.93 \pm 9580.94$ & $9058.82 \pm 7186.88$ & 199.74 & 0.005 \\
\hline Ferritin $(\mu \mathrm{g} / \mathrm{L})$ & $271.6 \pm 259.6$ & $238.13 \pm 259.8$ & 1.015 & 0.31 \\
\hline Duration of dialysis (months) $\ddagger$ & $26.11 \pm 31.80$ & $7.08 \pm 10.22$ & 5.42 & $<0.001$ \\
\hline
\end{tabular}

ESA = erythropoiesis-stimulating agent, SD = standard deviation, TSAT = transferrin saturation.

*Defined by a diagnosis of hypertension or a history of hypertension documented by a physician in the patient's chart.

†Any of the following diagnoses: coronary artery disease, atrial fibrillation, aortic stenosis, myocardial infarction, heart failure, left ventricular hypertrophy.

¥The calculated values presented here are based on 228 observations from patients in the conventional accelerated group and 85 observations from patients in the once-weekly group. 
This single copy is for your personal, non-commercial use only.

For permission to reprint multiple copies or to order presentation-ready copies for distribution, contact CJHP at cjhpedit@cshp.ca

Table 2. Multivariate Generalized Estimating Equations for Predictors of Outcomes for Study Participants

\begin{tabular}{|c|c|c|c|c|c|}
\hline \multirow[b]{2}{*}{ Model } & \multirow[b]{2}{*}{ Dependent Variable } & \multicolumn{2}{|c|}{ Iron Administration Protocol; Mean \pm SD } & \multirow[b]{2}{*}{ Wald $z$} & \multirow[b]{2}{*}{$p$ Value } \\
\hline & & Conventional Accelerated & Once Weekly & & \\
\hline 1 & Average TSAT percentage* & $23.5 \pm 9.7$ & $26.0 \pm 10.0$ & 5.99 & 0.014 \\
\hline 2 & Iron level $(\mu \mathrm{mol} / \mathrm{L}) \dagger$ & $8.69 \pm 3.94$ & $10.0 \pm 4.06$ & 7.04 & 0.008 \\
\hline 3 & Hemoglobin level (g/L)‡ & $112.1 \pm 11.05$ & $111.8 \pm 10.94$ & 0.54 & 0.46 \\
\hline 4 & Ferritin level $(\mu \mathrm{g} / \mathrm{L}) \S$ & $457 \pm 290$ & $331 \pm 280$ & 2.34 & 0.13 \\
\hline 5 & Total iron dose every 3 months $(\mathrm{mg})$ & $861.65 \pm 293.92$ & $828.71 \pm 291.87$ & 0.42 & 0.52 \\
\hline 6 & Weekly ESA utilization (units)** & $10706 \pm 9737$ & $7419 \pm 9814$ & 4.18 & 0.041 \\
\hline
\end{tabular}

ESA $=$ erythropoiesis-stimulating agent, TSAT $=$ transferrin saturation.

*Adjusted for baseline average TSAT percentage and total iron dose every 3 months (mg).

†Adjusted for baseline iron level ( $\mu \mathrm{mol} / \mathrm{L})$ and total iron dose every 3 months (mg).

¥Adjusted for baseline hemoglobin level ( $\mathrm{g} / \mathrm{L}$ ), baseline weekly ESA utilization (units), transfusion status, and total iron dose every 3

months (mg).

$\S$ Adjusted for baseline ferritin level ( $\mu \mathrm{g} / \mathrm{L})$ and total iron dose every 3 months (mg).

TAdjusted for baseline ferritin level ( $\mu \mathrm{g} / \mathrm{L})$, baseline TSAT percentage, and baseline iron level ( $\mu \mathrm{mol} / \mathrm{L})$.

**Adjusted for baseline weekly ESA utilization (units) and baseline hemoglobin level ( $\mathrm{g} / \mathrm{L}$ ).

record charting system, high workload and high staff turnover created multiple opportunities for doses to be missed and suboptimal record-keeping during the study period. The practice of standardizing administration times is advocated by the Institute for Safe Medication Practices (US) ${ }^{27}$ and the National Health Service $(\mathrm{UK})^{28}$ because of the potential to reduce patient harm. Upon conversion to once-weekly IV iron administration, nurses quickly became familiar with reviewing patients' charts and giving IV iron on specific days of the week; this change resulted in a reduction in the number of missed doses. Nurses' overall acceptance of the change was positive, although there were phone calls to the Pharmacy Department to obtain more medication early in the implementation phase. This practice change seemed like a "win-win" situation, with a reduction in missed doses, improvements in nurses' satisfaction, and minimal disruption to workflow in other departments.

The findings of this study suggest that, compared with conventional accelerated dosing regimen, once-weekly administration of iron can achieve comparable hemoglobin and ferritin levels and produce significantly higher average TSAT percentage and iron levels, while utilizing similar amounts of IV iron. These findings are especially important given that implementation of a once-weekly dosing regimen also resulted in a reduction in the use of ESA. As such, implementation of a once-weekly approach to iron dosing may prove beneficial in assisting clinicians to achieve targeted iron, hemoglobin, and TSAT levels without excessive use of ESA.

To the authors' knowledge, the methods and findings of this study are unique, as it is the first to quantify and compare the utility of a once-weekly iron dosing regimen and a conventional accelerated dosing regimen. Taylor and others ${ }^{23}$ followed 46 patients who were undergoing hemodialysis and who were given iron ferric gluconate $62.5 \mathrm{mg}$ IV twice weekly, weekly, or every 2 weeks for 6 months. Similar to the findings presented here, they reported a reduction in ESA use. However, unlike this study, Taylor and others ${ }^{23}$ used a univariate nonparametric approach and did not adjust for baseline scores, confounding variables, and the clustered nature of this type of repeated-observations data. In addition, they used an arbitrary ferritin cut-off of $100 \mathrm{ng} / \mathrm{mL}$, because data for this variable were not normally distributed. This approach is known to yield results that fail to assess the doseresponse relationship achieved in this study through square root transformation of the non-normally distributed variables.

Malovrh and others ${ }^{25}$ prospectively investigated the use of iron sucrose in 31 patients who were undergoing hemodialysis and compared their outcomes at the end of 2 periods (i.e., follow-up of 1 year and 4 years). In the first phase, patients received $100 \mathrm{mg}$ of iron sucrose no more than once weekly for 1 year; in the second phase, the same patients were treated with low-dose iron sucrose (10-60 mg) given 1-3 times per week every fourth week for the next 3 years. ${ }^{25}$ The study revealed a significant increase in hemoglobin B from the first phase to the second phase, with a decrease in iron use and minimal changes in ESA use. Serum ferritin, serum iron, and total iron-binding capacity were significantly decreased during the second phase. ${ }^{25}$ There was an improvement in response to ESA therapy with continuous low-dose administration of iron replacement therapy. Like Taylor and others, ${ }^{23}$ these authors did not compare their 2 approaches with the conventional accelerated approach. Therefore, it is unclear whether any of the approaches in these 2 studies was superior, inferior, or similar to the conventional standard of practice. In addition, the analysis by Malovrh and others ${ }^{25}$ was limited by the use of paired $t$ tests, as opposed to analysis with adjustment for the clustered nature of the repeated observations and potential confounders. In fact, in the study by Malovrh and others, ${ }^{25}$ baseline ESA use and duration of dialysis were significantly different between the study groups.

Despite the limitations of the 2 aforementioned studies ${ }^{23,25}$ and the fact that they did not compare conventional accelerated and alternative iron dosing regimens, each study had the goal of showing that alternative iron dosing regimens could achieve the required outcomes with less ESA and iron use. The findings 
of the current study support this hypothesis through direct comparisons between conventional and alternative iron dosing, suggesting that, after adjustment for baseline ESA scores for the 2 groups, the once-weekly iron regimen resulted in an adjusted absolute reduction of $8 \%$ in the utilization of ESA without compromising hemoglobin, ferritin, or TSAT levels.

This study had several limitations related to guideline changes for target hemoglobin during the study period, administration of 2 formulations of IV iron, and study design. During the second half of the study, the 2012 KDIGO guidelines were published, ${ }^{4}$ with a different hemoglobin target (100-115 g/L) than that presented in the guidelines for anemia management of the CSN (published in 2008: 100-110 g/L) and KDOQI (published in 2007: 110-120 $\mathrm{g} / \mathrm{L}$ ), which were the basis of the study hemoglobin targets $(100-120 \mathrm{~g} / \mathrm{L})$; the $2012 \mathrm{KDIGO}$ guidelines also had different considerations for initiation of IV iron. Despite these differences in guideline recommendations, the overall hemoglobin targets used in the current study overlapped both guideline ranges, and the use of IV iron most likely would not have been significantly affected if the target in the updated KDIGO guidelines had been followed. The approach to ESA dosing did not change over the entire study period, so potential confounding of ESA usage in the analysis was assumed to be minimal. Data for patients who received ferric gluconate and iron dextran were pooled in the analysis, which prevented analysis of the effect that different formulations might have had on the study outcomes. The most important limitation relates to the study design: because it was a retrospective review, incomplete documentation (such as missing information regarding whether or when IV iron was held for patients who had infections), difficulty in interpreting information in patients' charts, and differing quality of information documented by health care professionals may have introduced measurement bias. In addition, interpreting and reviewing administration records to calculate accurate results proved challenging for the study team; inter-rater variability was reduced by having only one person perform the data collection. Generalizability of the study results is limited because patient data were collected from a single Canadian hemodialysis centre. Finally, given the retrospective observational nature of the study, the possibility of confounding and measurement bias could not be ruled out. Thus, it is recommended that these findings be interpreted with caution.

\section{CONCLUSIONS}

The findings of this study suggest that initiation of a onceweekly iron dosing strategy uses the same amount of IV iron, achieves guideline-recommended targets for hemoglobin and iron indices, and significantly decreases the utilization of ESAs, relative to conventional accelerated iron dosing. The reduction in ESA use would likely translate into cost savings for the health care system without compromising patients' outcomes. However, given the retrospective nature of this study, the possibility of misclassification and measurement bias cannot be ruled out. Therefore, it is recommended that these findings be further investigated and replicated within the context of a prospective randomized controlled trial.

\section{References}

1. Kidney Disease Outcomes Quality Initiative, National Kidney Foundation. KDOQI clinical practice guidelines and clinical practice recommendations for anemia in chronic kidney disease. Am J Kidney Dis. 2006;47(5 Suppl 3):S11-145. Erratum in: Am J Kidney Dis. 2006;48(3):518.

2. Madore F, White CT, Foley RN, Barrett BJ, Moist LM, Klarenbach SW, et al. Clinical practice guidelines for assessment and management of iron deficiency. Kidney Int. 2008;74(Suppl 110):S7-11.

3. National Kidney Foundation, Kidney Disease Outcomes Quality Initiative. KDOQI clinical practice guideline and clinical practice recommendations for anemia in chronic kidney disease: 2007 update of hemoglobin target. New York (NY): National Kidney Foundation; 2007 [cited 2015 Jul 29]. Available from: http://www2.kidney.org/professionals/KDOQI/guidelines_ anemiaUP/

4. Kidney Disease: Improving Global Outcomes (KDIGO) Anemia Work Group. KDIGO clinical practice guideline for anemia in chronic kidney disease. Kidney Int Suppl. 2012;2(4):279-335.

5. Moist LM, Troyanov S, White CT, Wazny LD, Wilson J, McFarlane P, et al. Canadian Society of Nephrology commentary on the 2012 KDIGO clincial practice guideline for anemia in CKD. Am J Kidney Dis. 2013; 62(5):860-73.

6. Drüeke TB, Locatelli F, Clyne N, Eckardt KU, Macdougall IC, Tsakiris D, et al.; CREATE Investigators. Normalization of hemoglobin level in patients with chronic kidney disease and anemia. N Engl J Med. 2006;355(20): 2071-84.

7. Singh AK, Szczech L, Tang KL, Barnhart H, Sapp S, Wolfson M, et al.; CHOIR Investigators. Correction of anemia with epoetin alfa in chronic kidney disease. N Engl J Med. 2006;355(20):2085-98.

8. Pfeffer MA, Burdmann EA, Chin CY, Cooper ME, de Zeeuw D, Eckardt $\mathrm{KU}$, et al.; TREAT Investigators. A trial of darbepoetin alfa in type 2 diabetes and chronic kidney disease. N Engl J Med. 2009;361(21):2019-32.

9. Szczech LA, Barnhart HX, Inrig JK, Reddan DN, Sapp S, Califf RM, et al Secondary analysis of the CHOIR trial epoetin- $\alpha$ dose and achieved hemoglobin outcomes. Kidney Int. 2008;74(6):791-8.

10. For health professionals - important safety information and new prescribing information for the erythropoiesis-stimulating agents (ESAs), Aranesp (darbepoietin alfa) and Eprex (epoetin alfa). Ottawa (ON): Government of Canada; 2007 [cited 2015 Feb 27]. Available from: www.healthycanadians. gc.ca/recall-alert-rappel-avis/hc-sc/2007/14438a-eng.php

11. Information for healthcare professionals: erythropoiesis stimulating agents (ESA) [Aranesp (darbepoetin), Epogen (epoetin alfa), and Procrit (epoetin alfa)]. Silver Spring (MD): Food and Drug Administration (US); 2007 [cited 2015 Feb 27]. Available from: www.fda.gov/drugs/drugsafety/postmarket drugsafetyinformationforpatientsandproviders/ucm126481.htm

12. Kapoian T, O’Mara NB, Singh AK, Moran J, Rizkala AR, Geronemus R, et al. Ferric gluconate reduces epoetin requirements in hemodialysis patients with elevated ferritin. J Am Soc Nephrol. 2008;19(2):372-9.

13. Bailie GR, Hörl WH, Verhoef JJ. Differences in spontaneously reported hypersensitivity and serious adverse events for intravenous iron preparations: comparison of Europe and North America. Arzneimittelforschung. 2011;61(5):267-75.

14. Bailie GR, Larkina M, Goodkin DA, Li Y, Pisoni RL, Bieber B, et al. Data from the Dialysis Outcomes and Practice Patterns Study validate an association between high intravenous iron doses and mortality. Kidney Int. 2015;87(1):162-8

15. Pai AB, Boyd AV, McQuade CR, Harford A, Norenberg JP, Zager PG. Comparison of oxidative stress markers after intravenous administration of iron dextran, sodium ferric gluconate, and iron sucrose in patients undergoing hemodialysis. Pharmacotherapy. 2007;27(3):343-50.

16. Dexiron [product monograph]. Mississauga (ON): Bellco Health Care Inc; 2013.

17. Feraheme [product monograph]. Oakville (ON): Takeda Canada Inc; 2012

18. Ferrlecit [product monograph]. Laval (QC): Sanofi-Aventis Canada Inc; 2013.

19. Venofer [product monograph]. Mississauga (ON): Bellco Health Care Inc; 2013.

20. FDA drug safety communication: modified dosing recommendations to improve the safe use of erythropoiesis-stimulating agents (ESAs) in chronic kidney disease. Silver Spring (MD): Food and Drug Administration (US) 
2011 [cited 2015 Feb 27]. Available from: www.fda.gov/Drugs/DrugSafety/ ucm259639.htm

21. Ferrlecit product monograph. In: $e$-Therapeutics+. Ottawa $(\mathrm{ON})$ : Canadian Pharmacists Association; 2011 [cited 2015 Jul 25]. Database accessed through institutional licence.

22. Iron dextran product monograph. In: e-Therapeutics+. Ottawa (ON): Canadian Pharmacists Association; 2011 [cited 2015 Jul 25]. Database accessed through institutional licence.

23. Taylor JE, Peat N, Porter C Morgan AG. Regular low-dose intravenous iron therapy improves response to erythropoietin in haemodialysis patients. Nephrol Dial Transplant. 1996;11(6):1079-83.

24. Park J, Chang JW, Lee JS, Chun HC, Yang W, Lee SK, et al. Efficacy of low-dose i.v. iron therapy in haemodialysis patients. Nephrology (Carlton). 2009;14(8):716-22.

25. Malovrh M, Hojs N, Premru V. The influence of need-based, continuous, low-dose iron replacement on hemoglobin levels in hemodialysis patients treated with erythropoiesis-stimulating agents. ArtifOrgans. 2011;35(1):63-8.

26. Sheashaa H, El-Husseini A, Sabry A, Hassan N, Salem A, Khalil A, et al. Parenteral iron therapy in treatment of anemia in end-stage renal disease patients: a comparative study between iron saccharate and gluconate. Nephron Clin Pract. 2005;99(4):c97-101.

27. ISMP acute care guidelines for timely administration of scheduled medications. Horhsam (PA): Institute for Safe Medication Practices; 2011 [cited 2015 Feb 27]. Available from: www.ismp.org/tools/guidelines/acutecare/ tasm.pdf

28. Reducing harm from omitted and delayed medications in hospital. National Health Service (UK); 2011 [cited 2015 Feb 27]. Available from: www.nrls.npsa.nhs.uk/resources/type/alerts/?entryid45=66720
Marta Malkinska, BSc, BScPhm, ACPR, is with the Department of Nephrology, Sunnybrook Health Sciences Centre, Toronto, Ontario.

Wasim S El Nekidy, PharmD, BCPS, BCACP, is with the Department of Nephrology and the Department of Pharmacy, Windsor Regional Hospital, Windsor, Ontario.

Maher M El-Masri, PhD, RN, is with the Department of Nursing, University of Windsor, Windsor, Ontario.

Albert Kadri, MD, FRCPC, is with the Department of Nephrology, Windsor Regional Hospital, Windsor, Ontario.

Christine Donaldson, BScPhm, MEd, is with the Department of Pharmacy, Windsor Regional Hospital, Windsor, Ontario.

Derrick Soong, BSC, BScPhm, PharmD, is with the Department of Nephrology, Windsor Regional Hospital, Windsor, Ontario.

Competing interests: Derrick Soong reports personal fees and nonfinancial support from Takeda Canada for medical advisory board membership, as well as grant support from MedBuy outside the scope of the current article. No other competing interests declared.

\section{Address correspondence to:}

Marta Malkinska

Department of Nephrology

Sunnybrook Health Sciences Centre

2075 Bayview Avenue

Toronto ON M4N 3 M5

e-mail: marta.malkinska@sunnybrook.ca

Funding: Financial support for this study was provided through an unrestricted educational grant from MedBuy Canada.

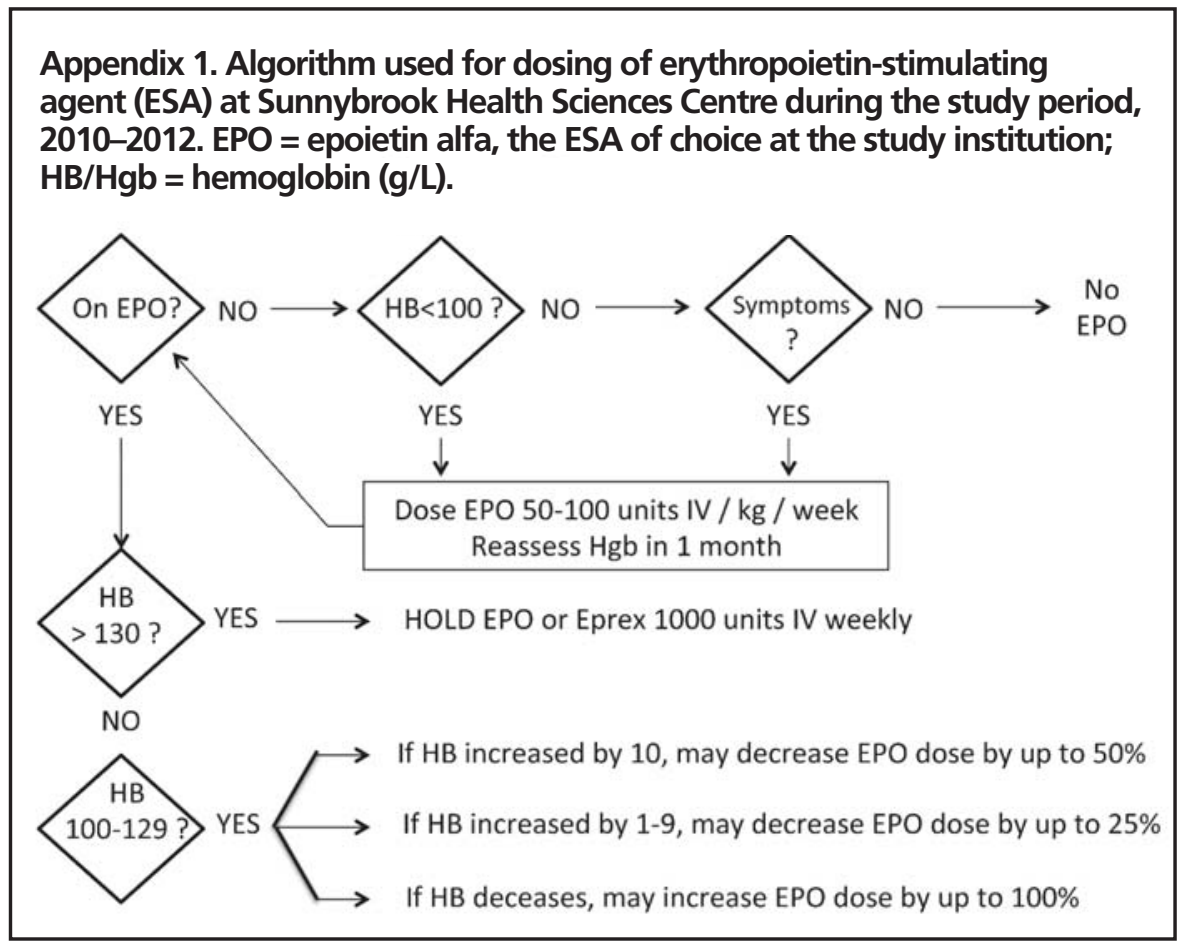

